\title{
Assessment of Postnatal Care Service Utilization and Associated Factors in Asella Town, Arsi Zone, Oromiya Regional State, Ethiopia
}

\author{
Amane Tumbure1, Deme Argaw ${ }^{1}$, Elile Fantahun ${ }^{1}$, Megersa Negusu1, ${ }^{1}$ Tsegaw Yitbarek ${ }^{1}$, Legese Tadesse ${ }^{2 *}$ and \\ Tewodros Desalegn ${ }^{2}$
}

${ }^{1}$ Associate professor of reproductive health, Asella Teaching Hospital, Arsi University, Ethiopia

${ }^{2}$ Department of Public Health, Asella College of Health Science, Arsi University, Ethiopia

Submission: July 17, 2018; Published: September 19, 2018

*Corresponding author: Legesse Tadesse MD, MPH, Associate professor of reproductive health, Asella Teaching Hospital, Arsi University, Ethiopia; Email: legesset2008@gmail.com

Summary

Post-natal care refers to the assistance given to the mothers and the babies for a period of six weeks from the time of delivery. It is believed to be low in Ethiopia. This study provided postnatal care service utilization information in the study area.

Objectives: To assess postnatal care service utilization prevalence in Asella Town, Arsi Zone, Ethiopia, 2017.

Method: Cross sectional community based descriptive study conducted on postnatal care service utilization among women delivered in the last two years Asela. Study carried out from August 01 to December 30/2017. Study cluster selected by using lottery method. A total of 209 households were included in the study. Data collected by using structured questionnaires. The collected data analyzed by using EPI Info version 3.5.4 and SPSS version 21. The result presented using tables, graphs and narrations.

Results: A total of 209 participants included and $99.3 \%$ responded with mean age of $26.7+4.4$ years. Hundred fifty six (74.2\%) heard about PNC while 152(72.7\%) reportedly used postnatal care service. Mothers with better education, antenatal follow up and appointment for postnatal care showed better proportion of postnatal care use.

Conclusion and recommendations: The overall prevalence of PNC service utilization in this study was $72.8 \%$. The quarter claimed did not know PNC service. The health care providers and policy makers are recommended to increase the awareness of mothers on postnatal care services. To schedule mothers based on the national postnatal care follow-up protocol in order to increase post-natal care service utilization.

Keywords: Postnatal care utilization; Prevalence; Asella town

Abbreviations: ANC: Ante Natal Care; EDHS: Ethiopian Demographic Health Survey; EMDG: Ethiopian Millennium Development Goal; HC: Health Center; MOH: Ministry Of Health; No: Number; NGO: Nongovernmental Organization; PNC: Postnatal Care; TBAs: Traditional Birth Attendants; UNICEF: United Nations International Children's Economic Fund; WHO: World Health Organization

\section{Background}

Post-natal care refers to the assistance given to the mother and the baby for a period of six weeks from the time of delivery. Maternal and child health are the major concern of public health organization and researchers throughout the world. Health education for mother is strategy many countries have adopted to improve maternal and child health. Yearly over half a million women encounter complication due to child birth and many die [1].

Post-natal services are the primary comprised of physiotherapy, physical examination, immunization, health education and family planning service [2]. Lack of care in this time period may result in death or disability as well as missed

opportunities to promote healthy behavior, affecting woman, newborn and children. Post-natal care is regarded as one of the most important maternal health care services for the prevention of impairment and disability resulting from child birth [3].

Different studies in developed countries showed the factor which affects utilization of post-natal care are distance from health service, cost including direct fees and cost of transportation, drug and supplies; multiple demands on women's time; women lack of power on decision making within the family; and poor quality of services including poor handling by health providers [4]. Half of all post-natal maternal death in Bangladesh occur during the first week after the baby is born, and the majority of these occurrences during the first 24 hours after child birth [5]. 


\section{Global Journal of Reproductive Medicine}

In a very poor countries and regions, such as those in subSaharan Africa only $5 \%$ of women receive post-natal care. In Ethiopia, factors associated to utilization of PNC service have been the major cause of maternal and infant death for majority of people, especially for those having low income. Therefore, it is important to assess the factor that cause underutilization of postnatal care service [6].

\section{Statement of the problem}

Approximately $80 \%$ of maternal death globally occur due to hemorrhage, sepsis, unsafe induced abortion, hypertensive disorder of pregnancy and obstructed labor [7]. These deaths are unjust and can be avoided with key health interventions, like provision of ANC and medically assisted delivery [8]. The emphasis on two out of eight critical united nation millennium development goals, that is reducing under five mortality by $2 / 3$, between 1990 and 2015 and reducing maternal mortality ratio by $3 / 4$ between 1990 and 2015 epitomize of the relevance of indicator sign global efforts towards human development [9]. A fully functioning mother-baby package intervention has been estimated to have post-natal cumulative effect of averting $75 \%-85 \%$ of maternal death in developing countries [10].

A woman living in sub-Saharan Africa high chance of dying in pregnancy, child birth and after child birth [11]. Post-natal service are also among the strategies aimed at preventing the onset of physical and mental impairments among women who have delivered [12]. Nearly 4.7 million mothers, newborns, and children die each year in sub-Saharan Africa: 265,000 mothers die due to complications of pregnancy and childbirth and 3,192,000 children, who survived their first month of life, die before their fifth birthday [13]. 1,208,000 babies die before they reach one month of age [14]; this toll of more than 13,000 deaths per day accounts for half of the world's maternal and child deaths. In addition, an estimated 880,000 babies are stillborn in sub-Saharan Africa and remain invisible on the policy agenda [15].

Despite remarkable progress to reduce mortality of children under 5 years of age in Ethiopia, little change has occurred in neonatal mortality, which accounts for $42 \%$ of all under- 5 deaths. The 2000 [16], 2005 [17], 2011 [18] and 2016 [19], Ethiopian Demographic and Health Surveys (EDHS) reported neonatal mortality rates of 49, 39, 37 and 35 per 1000 live births, respectively. The decline in neonatal mortality rates by $24 \%$ over 11 years is substantially less than the decline in infant (39\%) and child (60\%) mortality over the same period.

Use of maternal and newborn health care services is low in Ethiopia. According to the 2016 EDHS, only $62.4 \%$ of women who gave birth in the 5 years preceding the survey received any antenatal care from a skilled provider (eg, physician, midwife, nurse), and $9 \%$ received antenatal care from a health extension worker. Only $10 \%$ of women gave birth in a health facility or with a skilled birth attendant, and less than $1 \%$ gave birth with a health extension worker. Of note, only $7 \%$ of women received postnatal care within 48 hours of birth ( $6 \%$ from a skilled provider, $<1 \%$ from a health extension worker). Substantially fewer mothers and newborns living in rural areas received postnatal care, compared to those living in urban areas (3\% versus 32\%) [19].

Low use of postnatal care services by rural Ethiopian women may be due to the tradition of a 40 -day period of confinement to protect the mother and newborn from malevolent spirits [16]. However, other community-based projects in Ethiopia and elsewhere have achieved mixed results in terms of improving postnatal care coverage; none have achieved postnatal care coverage greater than $32 \%$ [19], even though the utilization of maternal health care service varies with the socio-economic characteristics of the population [20].

Significance of this study is taking in to consideration, that, post-natal health service utilization operates at various individual, house hold and community levels; authors aimed not only evaluating how postnatal care was conducted, but also tried describing why women did not receive postnatal care. Little is known in the study area on current magnitude of utilization of maternity services in health facilities especially postnatal care and associated factors for their utilization to the knowledge of the authors. This study, therefore, tried to assess extent of postnatal care utilization and attempted to describe factors that are assumed to be barriers to postnatal care utilization among mothers who gave birth. It provided relevant information to PNC programmers, Implementers and beneficent.

\section{Objectives}

\section{General objective}

To assess post-natal care service utilization and associated factors in Asella town, Arsi Zone, Oromiya Regional State, Ethiopia, 2017.

\section{Specific objectives}

To determine the prevalence of PNC utilization

To describe the women who utilized PNC in socio-demographic characteristics.

\section{Methods and Materials}

\section{Study area and period}

The study was conducted in Asella town. Asella is administrative town found in central Ethiopia, west of mount Chilalao. It is located in the Arsi zone which is one of the zones in Oromia Region divided into 26 districts, including two especial Administrative towns, namely Asella and Bokoji. Asella is the capital town of Arsi zone. It is located $175 \mathrm{KM}$ from Addis Ababa, capital city of Ethiopia has a latitude and longitude of $7^{\circ} 57^{\prime} \mathrm{N} 39^{\circ} 7^{\prime}$ Ewith an elevation of 2,430 meters. According to Ethiopian national census (CSA 2007), Assela town has a total population of 74,268 of whom 37,337 were male and 36,931 were females $[21,22]$. The study period was from March 14- September 30, 2017.

\section{Study design}

Community based descriptive cross sectional study was conduct to assess PNC utilization. 


\section{Population}

Source population: The source of population was all households' mothers in Asella town who gave birth in the last two years whose age is $15-49$ years.

Study population: Study of population was systematically select households whose mothers age is15-49 and who gave birth in the last 2 years.

Inclusion criteria: All mothers who gave birth in the last two years and who are volunteer for study.

Exclusion criteria: Mothers mentally ill or critically ill, and mothers who lost their children.

\section{Sample size calculation}

The required sample size was determined by using simple population proportion formula by considering $33.5 \%$ post-natal care service utilization [23].

$$
n=\frac{(Z \alpha / 2)^{2} p(1-p)}{d^{2}}
$$

Where,

$\mathrm{n}=$ the desired sample size

$Z \alpha / 2$ =standard normal score $(95 \%)$

$\mathrm{p}=$ prevalence of post-natal care service $(33.5 \%)$

$\mathrm{d}=$ degree of precision desired $(5 \%)$

Where,

$$
Z=1.96
$$$$
n=\frac{(1.96)^{2}(0.3)(1-0.5)}{(0.05)^{2}}=230
$$

- But since the source of the study subject considered below 10,000 we use the correction formula.

Therefore,

$$
\begin{aligned}
& \mathrm{nf}=\frac{\mathrm{ni}}{1+\mathrm{ni} / \mathrm{N}} \\
& \mathrm{nf}=\frac{230}{1+230 / 1824}=190+\text { non responsive rate }(10 \%)=209
\end{aligned}
$$

\section{Sampling technique}

Asella town has fourteen kebeles, among these kebele 09 was select by using Convenience method. There was 1824 total population. Number of females aged 15-49 years is 800 .There are seven ketenas in Assela kebele 09. The first ketene was select by using lottery method. Simple random sampling technique was conduct to select couples in each ketenas proportional to their number of currently married couples. The first household was select by lottery method and then $\mathrm{K}$ value will be used. $\mathrm{K}=$ total households $/$ sample size $=800 / 209=3.8=4$ every 4 th house hold was interview starting from the end of each village house until the allocated sample achieved. Couples who fulfilled the criteria of the study subject was interview and in the absence of illegible couples in that household the nearby household was interview (Figure 1).

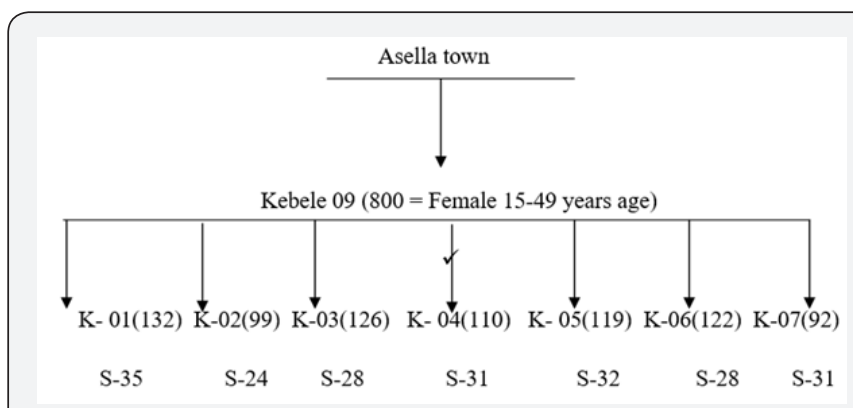

Figure 1: Schematic presentation of the sampling procedure. Keys: K- Ketenas, S- Sampled couple.

\section{Study variable}

Independent variable: Socio-demographic, reproductive factors, knowledge, accessibility

Dependent variable: Utilization of post-natal care

\section{Data collection procedures}

Data collection instrument: Data was collected using interview administered structured questionnaire. The principal investigator was involved in the data collection. A structured interviewer administered questionnaire was adapted by investigators after review of different literatures to collect the information based on study objective.

First the questionnaire was prepared in English language and then it was translated to local language (Amharic) and which was again back translated to English. Comparisons were made on the consistency of two versions. The variable to being collected includes socio demographic, economic and question on prevalence of PNC and awareness of people on risk associated with not use PNC.

Data processing and analysis: The Data were entered using EPI-INFO version 3.5.4 and exported to SPSS version 21 for analysis. After it was edited, sorted, organized, and checked for completeness. Descriptive statistics were carried out to characterize the study population using different variables. The result was presented by using table, graph and texts as based on type of data.

Data quality assurance: To assure the quality of collected data the following measure was under taken. The appropriately designed data collection instrument was used. Every day the collected data was cross checked by group members and comments and measures was being undertaken throughout the data collection period for completeness and consistency of the response. 


\section{Global Journal of Reproductive Medicine}

\section{Operational definitions}

i. Post-natal care: refers to the assistance given to the mother and the baby for a period of six weeks from the time of delivery.

ii. Utilization of service: It refers to use of post-natal service such as family planning, immunization and other services by women till six months after the delivery of the babies.

iii. Post-natal service: Is the service that consists of immunization, family planning and heath care education on child care, breast feeding, physiotherapy, physical examination, treatment and counseling service.

iv. Immunization: Is the process of administering vaccination to neonates, infant and child.

v. Conceptual frame work; A schematic presentation showing the association between factors and outcomes

vi. Puerperal sepsis: Is infection that occurs after delivery up to six weeks.

vii. Family planning: Is service important for spacing number of pregnancy and prevents unwanted pregnancy.

viii. Traditional birth attendants: Are unprofessional birth attendant who get skill from professionals.

\section{Ethical consideration}

Ethical clearance was taken from community and research committee. We were taken permission letter from Arsi University. Permission was being obtained from both the administrator to obtain the desired cooperation and participation.

Verbal informed consent was obtained from each study subject prior to the interview after the purpose of the study is explained to respondent. Confidentiality of the information was being assured and privacy of the respondent was being maintained. The respondents told to have the right to dropout the interview at any time she wishes. At the end of the interview, Information about advantage of postnatal care by skilled health professional explained to the respondents.

\section{Plan for dissemination of finding}

The final report will be presented to Arsi University, School of Health science, Department of public health. The result of the study will be disseminated to Assela health desk, Arsi zone health desk through seminar or written formal report. It will also be communicated to Arsi University College of Health Science staff members and students through the university library.

\section{Results}

\section{Socio demographic characteristics of the participants}

A total of 209 women participated in the study with a response rate of $99.3 \%$. Almost much of $(46.9 \%)$ of the participants were found between the age of 25 to 29 years. The mean age of the Participants was 26.7 years $(+\mathrm{SD}=4.4) .111(53.1 \%)$ of them were
Muslim and 193 (92.3\%) of them were married. With respect to level of education only 67(32.1\%) of the respondents had college and above education. The average monthly house hold income was 3948 ETB. More than half $129(61.7 \%)$ of the participants were using foot for manse of transportation to the health facilities (Table 1).

Table 1: Socio-demographic characteristics of the Women of Interviewed in Asella town Kebele 9, Arsi Zone Oromiya Regional state, Ethiopa, 2017. $(n=209)$.

\begin{tabular}{|c|c|c|}
\hline Variables & Frequency (no) & Percentage (\%) \\
\hline \multicolumn{3}{|c|}{ Age } \\
\hline$<20$ years & - & - \\
\hline 20-24 years & 19 & 9.1 \\
\hline 25-29 years & 98 & 46.9 \\
\hline 30-34 years & 59 & 28.2 \\
\hline$>=35$ years & 33 & 15.8 \\
\hline \multicolumn{3}{|c|}{ Religion } \\
\hline Orthodox Christian & 70 & 33.5 \\
\hline Muslim & 111 & 53.1 \\
\hline Protestant Christian & 28 & 13.4 \\
\hline \multicolumn{3}{|c|}{ Marital status } \\
\hline Married & 193 & 92.3 \\
\hline Single & 2 & 1 \\
\hline Divorced & 14 & 6.7 \\
\hline \multicolumn{3}{|c|}{ Educational status } \\
\hline Noformal education & 22 & 10.4 \\
\hline Primary school & 50 & 23.9 \\
\hline Secondary school & 70 & 33.5 \\
\hline College and above & 67 & 32.1 \\
\hline \multicolumn{3}{|c|}{ Paternal educational status } \\
\hline No formal education & 120 & 57.4 \\
\hline Primary school & 46 & 22 \\
\hline Secondary school & 32 & 15.3 \\
\hline College and above & 11 & 5.3 \\
\hline \multicolumn{3}{|c|}{ Occupation of participants } \\
\hline House wife & 77 & 36.8 \\
\hline Employed/government & 75 & 35.9 \\
\hline Merchant/daily labor & 39 & 18.7 \\
\hline Other & 18 & 8.6 \\
\hline \multicolumn{3}{|c|}{ Family monthly Income } \\
\hline$<500$ Eth Birr & 2 & 1 \\
\hline 500-1999 Eth Birr & 34 & 16.5 \\
\hline 2000-3999 Eth Birr & 66 & 31.2 \\
\hline 4000-6999 Eth birr & 83 & 39.8 \\
\hline >=7000 birr & 24 & 11.5 \\
\hline \multicolumn{3}{|c|}{ Means of transport to Health center } \\
\hline By Foot & 129 & 61.7 \\
\hline By Taxi & 69 & 33 \\
\hline By your own car & 11 & 5.3 \\
\hline
\end{tabular}




\section{Global Journal of Reproductive Medicine}

\section{Reproductive characteristics of the participants}

Table 2: Reproductive characteristics of the Women interviewed in Asella town Kebele 9 Arsi Zone Oromiya Regional state, Ethiopa, 2017. $(n=209)$.

\begin{tabular}{|c|c|c|}
\hline Variable & Frequency(no) & Percentage (\%) \\
\hline \multicolumn{3}{|c|}{ History of abortion } \\
\hline Yes & 33 & 15.8 \\
\hline No & 176 & 84.2 \\
\hline \multicolumn{3}{|l|}{ Parity } \\
\hline Para I & 39 & 18.7 \\
\hline Para II-III & 164 & 78.7 \\
\hline Para $>=$ IV & 6 & 2.9 \\
\hline \multicolumn{3}{|c|}{ Nature of Index pregnancy } \\
\hline Planned/supported & 135 & 64.6 \\
\hline Unplanned/unsupported & - & - \\
\hline \multicolumn{3}{|c|}{ History of ANC } \\
\hline Yes & 180 & 86.1 \\
\hline No & 29 & 13.9 \\
\hline \multicolumn{3}{|c|}{ Number of ANC visits $(n=180)$} \\
\hline One times & 11 & 6.1 \\
\hline Two times & 89 & 49.2 \\
\hline Three times & 70 & 39.2 \\
\hline Four and above times & 10 & 5.5 \\
\hline \multicolumn{3}{|c|}{ Place of delivery } \\
\hline Home & 5 & 2.4 \\
\hline Health center & 73 & 34.9 \\
\hline Government hospital & 124 & 59.3 \\
\hline Private hospital & 7 & 3.3 \\
\hline Private clinic & - & - \\
\hline \multicolumn{3}{|c|}{ Did you give appointment for postnatal care before discharge } \\
\hline Yes & 151 & 72.2 \\
\hline No & 58 & 27.8 \\
\hline \multicolumn{3}{|c|}{ Appointed within $2-4$ weeks $(n=151)$} \\
\hline Yes & 47 & 32.2 \\
\hline No & 104 & 69 \\
\hline \multicolumn{3}{|c|}{ Appointed at 4 weeks } \\
\hline Yes & 16 & 10.5 \\
\hline No & 134 & 88.8 \\
\hline \multicolumn{3}{|c|}{ Appointed at 6 weeks } \\
\hline Yes & 89 & 58.5 \\
\hline No & 62 & 41.4 \\
\hline
\end{tabular}

About $176(84.2 \%)$ of the participants didn't have history of abortion,33(15.8\%) have history of abortion. More than Half $164(78.5 \%)$ of the participants were multi gravid 135 (64.6\%) of the previous pregnancy were Planned and support, 74(35.4\%) was unplanned and support. More than half 180(86.1\%) respondents had ANC follow up at least one, on top participants were $209(100 \%)$. Three fourth $151(72.2 \%)$ of the participants were given appointment for postnatal care by the health care professionals before discharge. The remaining 58(27.8\%) participants were not informed to have postnatal care by the health professionals before discharge from the health institution. Among women who gave birth $124(59.3 \%)$ in governmental hospital, health center $73(34.9 \%, 7(3.3 \%$ in privet clinic and home delivery 5(2.4\%) (Table 2).

\section{Prevalence of postnatal care utilization}

Table 3: Prevalence and characteristics of postnatal care utilization of Interviewed women Asella town Kebele 9 Arsi Zone Oromiya Regional state, Ethiopa,2017.

\begin{tabular}{|c|c|c|}
\hline Variables & Frequency & Percentages (\%) \\
\hline \multicolumn{3}{|c|}{ Did you have postnatal care $n=209$} \\
\hline Yes & 152 & 72.7 \\
\hline No & 57 & 27.3 \\
\hline \multicolumn{3}{|c|}{ Place of postnatal care $(n=152)$} \\
\hline Health center & 70 & 46 \\
\hline Gov't hospital & 75 & 49.3 \\
\hline Private hospital & 7 & 4.5 \\
\hline \multicolumn{3}{|c|}{ Postnatal care within 2 weeks of } \\
\hline \multicolumn{3}{|l|}{ discharge $(n=152)$} \\
\hline Yes & 23 & 15.1 \\
\hline No & 129 & 84.9 \\
\hline \multicolumn{3}{|c|}{ Postnatal care after 4 weeks of discharge $n=152$} \\
\hline Yes & 65 & 42.7 \\
\hline No & 87 & 57.3 \\
\hline \multicolumn{3}{|c|}{ Postnatal care at six weeks of postpartum $n=152$} \\
\hline Yes & 58 & 38.2 \\
\hline No & 39 & 61.8 \\
\hline \multicolumn{3}{|c|}{ Number of postnatal care visit $n=152$} \\
\hline Two times & 17 & 11.1 \\
\hline Three times & 78 & 51.3 \\
\hline Four or more times & 57 & 37.5 \\
\hline \multicolumn{3}{|c|}{ Did your baby was with you during postnatal care $\mathrm{N}=152$} \\
\hline Yes & 147 & 96.7 \\
\hline No & 5 & 3.2 \\
\hline
\end{tabular}

About 152(72.7\%) had PNC and 57(27.3\%) didn't have any PNC visit. The most frequent place of postnatal care were at government hospitals $75(49.3 \%)$ followed by the health centers $70(46.0 \%)$. The proportion of postnatal care visit across 2 weeks of discharge, after four week of discharge and at six weeks of postpartum were 23(15.1\%), 65(42.7\%) and 58(38.2\%) respectively. Contraceptive use after delivery 118(56.4\%) Contraceptive initiation period At 6 month 86(71.1\%) (Table 3).

Concerning what was done for the women during postnatal care visit we found that nearly half $56.1 \%$ of the respondents provided contraceptives, $3.9 \%$ had physical examination, $16.8 \%$ advice on danger signs, $18.1 \%$ provided TT vaccination, and $3.2 \%$ had laboratory investigations (Figure 2). Concerning what was done for the baby as it displayed on Figure 3, 87.5\% of the babies had received immunization, $9.2 \%$ of women were counseled 


\section{Global Journal of Reproductive Medicine}

about danger signs of their baby, and only $0.7 \%$ of the babies had physical examination and $0.7 \%$ laboratory investigation (Figure 3).

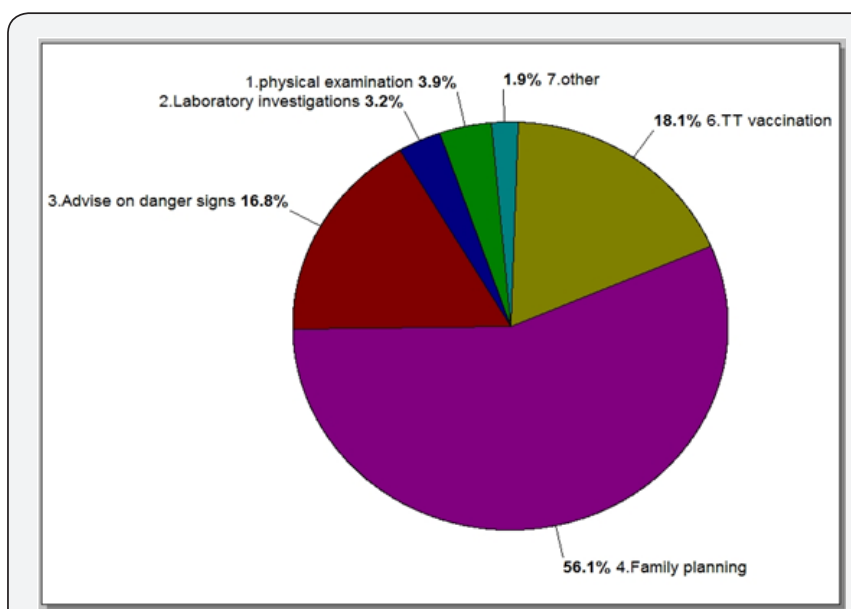

Figure 2: Post-natal care service provided to the women during their postnatal care visit.

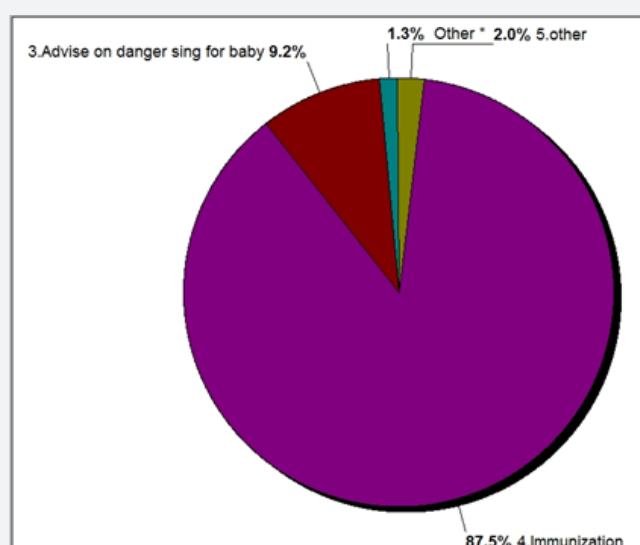

- Other, 1 physical Examination 0.7\%, 2 Laborator $0.7 \%$

Figure 3: Proportion of the services given to the baby during postnatal care visit.

\section{Knowledge and awareness about PNC}

Percent of women aware of service type

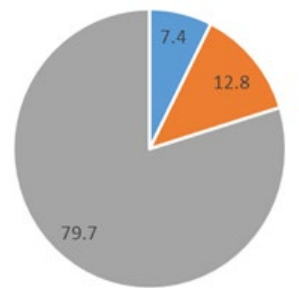

- Treatment a Family planning = Immunization

Figure 4: proportion of participant having awareness about services provided during PNC visit.

About 156(74.2\%) heard about PNC,53(25.4\%) didn't heard about PNC. From this who heard about PNC from Health works 118(75.6\%), 26(16.7\%) from mass media,12(7.7\%) from neighbor.135(84.1\%) know what is given in PNC,21(15.9\%) didn't know.

As shown in the Figure 4 women participated in study know PNC service as immunization $79.7 \%$, Family planning $12.8 \%$ and treatment $7.4 \%$.

\section{Determinant of postnatal care utilization}

Out of twenty independent variables categorized under Socio demographic, reproductive characteristic, knowledge, Six variables namely educational status, ANC follow up, whether or not PNC appointment given, were determinant of post-natal care utilization in our study (Figure 5). Over all 57(27.3\%) of respondents were not using PNC, the major reasons explained by these Women were being not appointed by the health care provider $68.4 \%$ and lack of knowledge on the importance of PNC service and $31.4 \%$ (Figure 5).

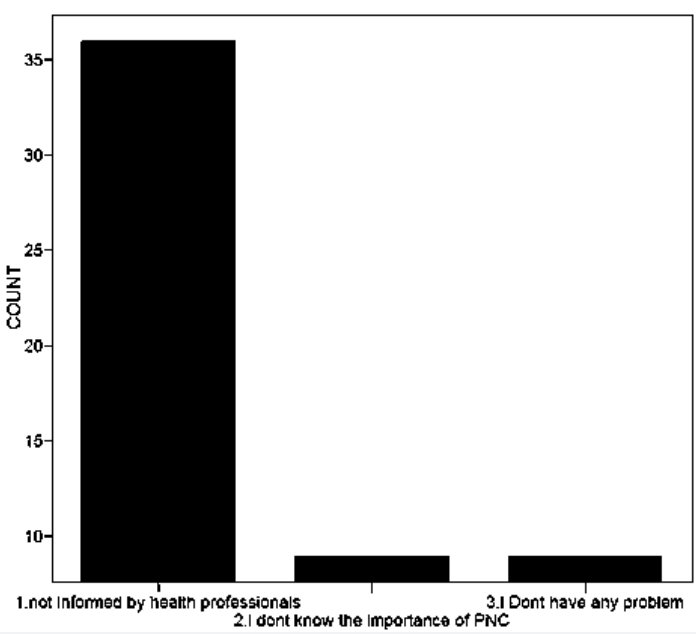

Figure 5: Reasons for not attending postnatal care services given by the study participants at Asella town Kebele 9 Arsi Zone Oromiya Regional state, Ethiopa,2017.

\section{Discussion}

Post-natal care is one of the components of maternal and child health which plays an important role in the prevention of complications that occurs following delivery of the new baby. This study tried to assess the prevalence and knowledge of postnatal care utilization among selected village Assela Town of Arsi Zone, Ethiopia. The selected socio-demographic status of the participants showed most of them 193(92.3\%) married, 164(78.5 \%) were multiparous and 22(10.4\%) were illiterate. This study indicated that $(72.7 \%)$ of the participants had received a health checkup after delivery despite the fact that almost all women were given birth at health institution 204(97.6\%). But this figure is very high when compared with the 2016 EDHS postnatal care utilization rate of $9.0 \%$ and $18.8 \%$ of institutional delivery rate respectively [5]. This difference might be due to the time difference and the presence of diverse intervention to improvement in accessing and utilizing maternal health care service in the urban area as the case in current study. This study finding on PNC prevalence was also higher than three similar studies conducted in Enderta District, 


\section{Global Journal of Reproductive Medicine}

Tigray, 49.7\%) [24], Jabitena District, Amhara Region (20.2\%) [25], and South Nation and Nationality Region (37.2\%) in Ethiopia [26]. The discrepancies might be associated with the variation in the study areas and as well study population.

Similarly, the postnatal care utilization of this study finding also a bit higher when compared to the studies conducted in African and Asian countries; the prevalence of not using postnatal care in Bangladesh (73\%), Nepal (72\%), Rwanda (71\%), Burkina Faso (44\%), Cambodia (46\%), Haiti (55\%), and Kenya (46\%) Malawi (41\%).

Concerning the quality of postnatal care provided by the health professional, it was found that about more than half $(56.1 \%)$ of the women were reportedly provided only contraceptives and less than one in three women received the remaining postnatal care services such as counseling on danger signs, physical examination, and health promotion. Similarly, the postnatal care provided to their babies mainly focused on providing immunization (87.5\%). The remaining services accounted for less than $11.3 \%$. This was also true in a study done in southern Ethiopia [26].

The key determinantfactor for PNC utilization in our study were educational status, ANC follow up, provision of PNC appointment given by health provider. Women who were counseled and given appointment for postnatal care service were utilized the PNC service higher than those women who didn't informed about the PNC service on discharge. This was also supported by the reason given by those women who didn't utilized PNC during this study. Similarly, a study done in northern Ethiopia found that those women who had got information about postnatal care services from Health Extension Workers and Midwife/Nurse had larger oddis (24.87) to attend postnatal care service compared to those women who had got information from other sources [25]. This finding may lead to a conclusion that the PNC service utilization is strongly influenced by the knowledge of women on postnatal care benefits.

Those mothers with secondary levels of education had more postnatal care utilization than mothers who didn't have formal education. A study done on the assessment of factors affecting utilization of postnatal care services was conducted in Jabitena district, Amhara regional state in Ethiopia found that among the socio-demographic factors, the key predictor for PNC utilization was educational status of the respondents. A participant whose level of education was secondary school and above showed better utilization of PNC service as compared to illiterate women $[25,26]$, similarly a study done in Nepal found that mothers who were educated had better score of using [27].

History of ANC follow up was one of the strongest predictors of postnatal care service utilization mothers who have history of ANC follow up utilize PNC more than women who didn't have ANC follow up. Another community based study done in northern Ethiopia found that women who had ANC follow up were 4 times more likely to attend postnatal care services as compared to women who didn't had [28]. A study done in Nepal a woman who had attended a four or more antenatal were more likely to report attending at least one postnatal care visit [27]. This is because it improves the knowledge of better outcome of having post-natal care service.

\section{Strength and Limitation}

\section{Strength of the study}

The source of the data for this study was based on the selfreport of respondents and provided no validation of obtained information with any objective source such as health facility cards. A high response rate of $99.3 \%$ gained from the participants of the study.

\section{Limitation of the study}

Using non probability sampling method was one limitation. Recall bias was more likely since women were asked for events which have already happened within the past two years prior to this study despite the consideration of recent births. Study design was descriptive cross sectional and not association done to show determinants. Use of health professionals as data collectors may create bias as they might direct the respondents during the data collection.

\section{Conclusion}

The overall prevalence of PNC service utilization in this study was relatively good as compared to Oromiya region $77 \%$ of women use post-natal care. In Arsi zone 78\% of women use post-natal care utilization in 2009, also the same in Tiyo woreda, but it is very high compare to EDHS 2016 Oromyia $9.0 \%$ of women had postnatal care in the first 2 days after delivery. To enhance PNC service utilization all women should be counseled about postnatal period and provided appointment. The health care providers and policy makers are recommended to increase the awareness mothers on postnatal care services, to prevent maternal and neonatal complication and to schedule mothers based on the national postnatal care follow-up protocol in order to increase post-natal care service utilization.

\section{Recommendations}

a. To health professionals: Should be counsel about the danger signs of postnatal period and give appointment for PNC.

b. To health facilities: Should assure comprehensive and quality of postnatal care services. Should give continuous training for health care providers on PNC appointment and counseling about danger sign during postnatal period

c. To Health bureau: Should emphasize the improvement of quality of service PNC utilization. Should prepare guide lines on danger sign during Post-natal care visit.

\section{Acknowledgement}

Authors acknowledge Arsi University College of Health Science and all the participants for this research work to be accomplished. 


\section{Global Journal of Reproductive Medicine}

\section{References}

1. Maine D (1981) Family Planning: its impact on the health of women and children. New York, Columbia University, Center for Population and Family Health.

2. Ashford L (2004) Hidden suffering disabilities from pregnancy and child birth in less developed countries, Population Reference Bereau 123(12): 420-423.

3. WHO (1998) Postpartum care of mother and newborn: a practical guide. World Health Organization, Geneva, Switzerland.

4. Cunningham F, Garry ED (2002) Williams obstetric. 21 New York, M.C. Graw Hill, 67(13): 89-96.

5. Hill K, Sham-El-Ariteen, Hefizur RC, Saitur R (2000) Adult Female Mortality in Bangladesh: levels and causes. 67(13): 89-96.

6. Yanagisawa S, Oum S, Wakai S(2015) Determinant of skilled birth attendant in rural Cambodia.

7. World Health Organization (2005) World Health Report. World Health Organization, Geneva, Switzerland.

8. Adam T, Lim SS, Mehta S, Bhutta ZA, Fogstad H, et al. (2005) Cost effectiveness analysis of strategies for maternal and neonatal health in developing countries. BMJ 331(7525):1107.

9. Freedman LP, Graham WJ, Brazier E, Smith JM, Ensor T, et al. (2007) Practical lesson from global safe motherhood initiative: Time for a new focus on implementation. Lancet 370(9595): 1383-1391.

10. Graham Wendy J, Cairns John, Bhattecharya Sohinee, Bullough Colin, Quagyumzahidul, et al. (2006) Washington DC: World Bank and Oxford university press, Second edition Pp: 499-529.

11. Chakraborty N, Islam MA, Chowdhury RI, Bari W (2005) Utilization of postnatal care in Bangladsh. Health Soc Care Community 87(19): 98103

12. Ministry of Health (2006) Federal Democratic Republic of Ethiopia National Reproductive health strategy (2006-2015). FMOH, Addis Ababa, Ethiopia.

13. UNICEF (2009) State of world children. New York UNICEF.

14. Bryce J, Reguejo JA (2010) Tracking progress in maternal, a newborn and child survival: the 2010 Report New York, UNICEF.

15. Stanton c, Lawn JE, Rahma H, Wilczynska-Ketende K, Hill (2006) still birth rate; delivering estimates in 190 countries. Lancet 367(9521): 148714-94.



This work is licensed under Creative Commons Attribution 4.0 License OI: 10.19080/GJORM.2018.06.555678
16. Central Statistical Agency (2001) Ethiopia Demographic and Health Survey 2000. Addis Ababa, Ethiopia: Central Statistical Agency and Calverton, Maryland: USA: ORC Macro.

17. Central Statistical Agency (2006) Ethiopia Demographic and Health Survey 2005. Addis Ababa, Ethiopia. ORC Macro Calverton, Maryland, USA.

18. Central Statistical Agency (2012) Ethiopia Demographic and Health Survey. Addis Ababa, Ethiopia. ORC: and ICF Macro, Calverton, Maryland: USA, 2011.

19. Central Statistical Agency (2016) Ethiopia Demographic and Health Survey: Addis Ababa: Central statistical agency.

20. Seims LR (2008) Postnatal care of newborns and mothers in developing countries. J Health Popular Nutr 26(1): 110-111.

21. Bick DE, MacArthur C (1995) Attendance, content and relevance of the six week postnatal Examination. Midwifery 11(2): 69-73.

22. Assela town Administer office (2010) Arsi, Oromia, Ethiopia, unpublished report. (unpublished document)

23. Miteku A, Zerfu M, Berihun A (2016) Post- natal care service utilization and associated Factors among women who gave birth in the last 12 months prior to the study in Debre Markos Town, Northwestern Ethiopia. Community-based cross sectional Study. International Journal of Reproductive Medicine 1155: 1-7.

24. Matijasevich A, Santos S, Silveira M, Domingues M, Barros A, Marco P et al. (2009) Inequities in maternal postnatal visits among public and private patients: 2004 Pelotas Cohort study. BMC Public Health 9: 335.

25. Gebeyehu Y, Desta W, Hailu (2014) A: Factors Affecting Utilization of Postnatal Care Service in Jabitena District, Amhara Region, Ethiopia. Science Journal of Public Health 2(3): 169-176.

26. Regassa N (2011) Antenatal and postnatal care service utilization in southern Ethiopia: a Population -based study, African Health Sciences 11(3): 390-397.

27. Khanal V, Adhikari M, Karkee R, Gavidia T (2014) Factors associated with the utilization of postnatal care services among the mothers of Nepal: analysis of Nepal Demographic and Health Survey 2011. BMC Women's Health 14: 19

28. Aregay A, Alemayehu M, Assefa H, Wondeweson W (2014) Factors associated with maternal health care services in Enderta District, Tigray, and Northern Ethiopia: A cross sectional study. American Journal of Nursing Science 3(6): 117-125.

\section{Your next submission with Juniper Publishers will reach you the below assets}

- Quality Editorial service

- Swift Peer Review

- Reprints availability

- E-prints Service

- Manuscript Podcast for convenient understanding

- Global attainment for your research

- Manuscript accessibility in different formats

( Pdf, E-pub, Full Text, Audio)

- Unceasing customer service

Track the below URL for one-step submission

https://juniperpublishers.com/online-submission.php 